\title{
DIVERSIFIKASI PANGAN OLAHAN BERBASIS KACANG TANAH UNTUK MENINGKATKAN PEREKONOMIAN MASYARAKAT DI DESA PILOHAYANGA BARAT
}

\author{
Siti Aisa Liputo ${ }^{1)}$, Zainuddin Antuli ${ }^{2)}$, Yoyanda Bait ${ }^{3)}$ \\ Fakultas Pertanian, Universitas Negeri Gorontalo ${ }^{1)}$ \\ E-mail: sweetydanizh@gmail.com
}

\begin{abstract}
This activity dedicated to help the people of peanut laobor mers in West Pilohayanga Village to improve the processing of various peanut become product as their skills, also to motivated them in business developing. Beside that, another purpose that the peanut labor that only provide raw material of peanut, can be processing become processed and selling the product directly as their own business, it has an increase the people income. The method used in this activity is a participatory approach that provide education and community training with the academis team (students and lecturer), also conducted the formation of UMKM, and UMKM mentoring in their production, promotion, and selling with the students role as fasilitator. In this community service in addition to community training is also give an business assistance there are tools and materials of peanut processing. The training attended by 30 people consist of PKK and Dasawisma women community. The products formed in this training are Egg Nuts, Kentucky Nut, and peanut butter. From this training, 3 UMKM formed, they are Hidayah UMKM, Berkah UMKM, and Bersahaja UMKM. The average product has a high degree of preference, which means it can be accepted by the panelists.
\end{abstract}

Keyword : Pengolahan kacang tanah, kacang kentucky, kacang telur, selai kacang, Kacang PILBAR 


\section{PENDAHULUAN}

Desa Pilohayanga Barat merupakan salah satu desa yang terletak di Kecamatan Telaga Kabupaten Gorontalo. Desa Pilohayanga Barat memiliki luas wilayah sekitar $17 \mathrm{~km}^{2}$ dengan jumlah penduduk sekitar 1030 jiwa yang terdiri dari yang tersebar di 2 Dusun. Desa pilohayanga barat merupakan desa hasil pemekaran dari Desa induk Pilohayanga. Umumnya mata pencaharian masyarakatnya adalah penjual kacang tanah.

Potensi terbesar dari Desa Pilohayanga Barat adalah Hasil Pertanian dan Peternakan. Luas lahan pertanian yang ada di Desa Pilohayanga Barat adalah sebesar $100 \mathrm{Ha}$. Salah satu komoditi yang banyak diusahakan oleh masyarakat petani di Kecamatan Telaga termasuk di Desa Pilohayanga Barat adalah kacang tanah. Akan tetapi kacang tanah ini bukan dari hasil pertanian masyarakat setempat, melainkan dipasok dari beberapa daerah penghasil kacang tanah, khususnya di Kabupaten Gorontalo. Mereka memasok kacang tanah dari beberapa petani kacang untuk dijual kembali di beberapa pasar tradisional. Kacang yang dijual masih dalam bentuk kacang mentah yang telah dipipil, kemudian dijual per liter. Melimpahnya ketersediaan kacang tanah di Kecamatan Telaga khususnya di Desa Pilohayanga Barat belum dimanfaatkan secara optimal. Padahal potensi ini membuka peluang kegiatan usaha bagi masyarakat. Namun Hasil produksi kacang tanah selama ini hanya dijual dalam bentuk kacang tanah kering pipil ataupun dalam bentuk segar tanpa melakukan pengolahan lebih lanjut untuk meningkatkan nilai tambah.

Komoditas kacang tanah di Desa Pilohayanga Barat hanya dipasarkan dalam bentuk primer (kacang tanah segar) atau kacang tanah kering pipilan dengan nilai jual yang rendah. Harga kacang tanah segar pipilan di pasaran sekitar Rp.28.000/Kg. Nilai jual kacang tanah yang sangat rendah tersebut menyebabkan pendapatan petani kacang tanah masih rendah sehingga komoditas kacang tanah belum mampu meningkatkan kesejahteraan masyarakat.

Potensi komoditas kacang tanah di Desa Pilohayanga Barat belum mendapat sentuhan teknologi pengolahan. Hal ini terlihat tidak adanya industri-industri rumah tangga yang mengolah bahan baku kacang tanah menjadi produk olahan. Minimnya hasil diversifikasi olahan berbasis kacang tanah di Desa Pilohayanga Baratdisebabkan karena kurangnya informasi teknologi dan terbatasnya pengetahuan serta keterampilan masyarakat desa mengenai usaha diversifikasi kacang tanah. Upaya transfer informasi teknologi pengolahan kacang tanah melalui kegiatan pelatihan adalah cara yang efektif untuk dilakukan pada masyarakat Desa Pilohayanga Barat yang memiliki latar belakang pendidikan yang rendah.

\section{Target Kegiatan}

Dari kegiatan ini diharapkan kelompok sasaran dapat memperoleh keterampilan pengolahan berbagai macam produk berbahan baku kacang, sehingga secara bertahap mereka termotivasi mengembangkan usaha dengan pola pikir bisnis-komersial. Selain itu diharapkan peran pengumpul kacang yang selama ini hanya menyediakan bahan baku dapat mengolah menjadi produk olahan dan memasarkan sendiri sehingga berdampak pada perbaikan pendapatan pengumpul.

\section{Luaran dari kegiatan ini adalah :}

Produk olahan dari kacang dengan berbagai macam jenis yang dikemas dengan kemasan yang menarik dan memenuhi persyaratan untuk dijual ke pasar modern.

\section{METODE KEGIATAN}

Kegiatan ini dilakukan dengan menggunakan pendekatan partisipatif yaitu melaksanakan pendidikan dan pelatihan masyarakat dengan pihak akademisi (Dosen Pembimbing Lapang (DPL dan mahasiswa). Pendekatan partisipatif adalah memberdayakan masyarakat agar mampu mendukung pembangunan sumber daya manusia secara berkelanjutan (Saragih. 2002 dalam Lay. dkk 2004).

Selain pemberian pelatihan, dalam pengabdian ini akan dibentuk krlompok usaha masyarakat yang bisa menjalankan usaha pengolahn kacang. Kemudian dilakukan pendampingan oleh mahasiswa kepada kelompok usaha masyarakat yang telah 
terbentuk, dalam hal produksi, promosi, dan penjualan.

\section{HASIL DAN PEMBAHASAN}

\section{Pelatihan Pengolahan Kacang Tanah}

Kegiatan pelatihan dilaksanakan selama 1 hari yaitu tanggal 17 Juli 2017 bertempat di kantor Desa Pilohayanga Barat. Pelatihan ini diikuti oleh sekitar 30 orang yang tergabung dalam dasa wisma di Desa Pilohayanga Barat. Selama pelaksanaan pelatihan, peserta didampingi oleh mahasiswa KKN yang dibagi menjadi 3 kelompok.

Kegiatan pelatihan diawali dengan pembukaan yang dihadiri oleh Kepala Desa Pilohayanga barat, Camat setempat, kepalakepala desa tetangga, Ketua Tim PKK bersama aparat Desa serta seluruh mahasiswa KKNPPM. Dalam acara pembukaan tersebut, dilakukan penyerahan bantuan peralatan yaitu masing-masing kelompok masyarakat diberikan 1 paket alat pengolahan, yang terdiri atas mixer, food processor, kompor gas, wajan, wadahwadah plastik, dan alat-alat pengemasan.

Sebelum kegiatan praktikum dilakukan, terlebih dahulu diberikan materi mengenai prospek produk, tahapan proses, teknik pengemasan dan pelabelan, Good Manufacture Process (GMP) dan teknik pemasarannya. Kegiatan praktikum terdiri dari beberapa tahap yaitu penyiapan dan penimbangan komposisi bahan baku, proses pemasakan, pengemasan dan pelabelan.

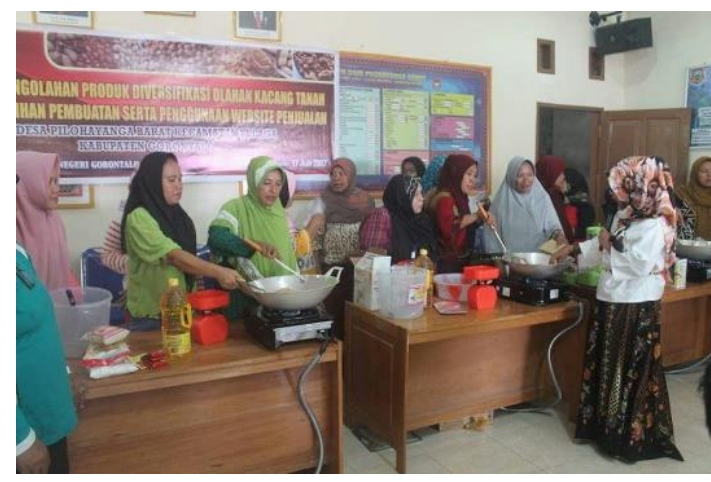

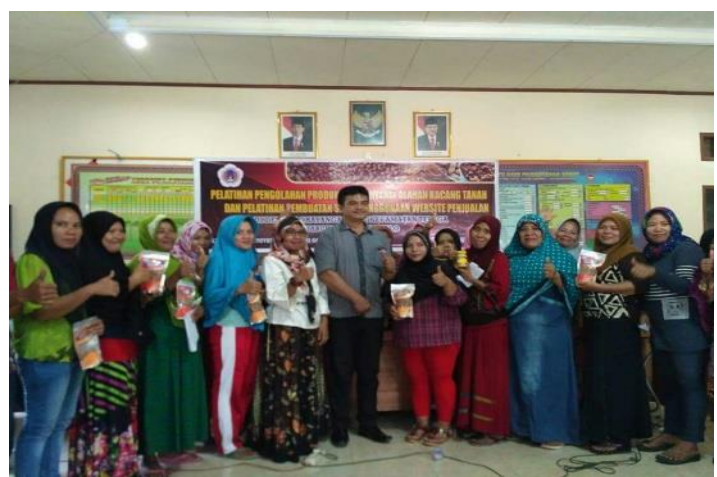

Gambar 1. Kegiatan Pelatihan

Diversifikasi Olahan Kacang

Desain label dari masing-masing yang digunakan sudah didesain oleh mahasiswa KKN-PPM. Produk yang dihasilkan antara lain kacang telur, kacang Kentucky, dan selai kacang. Kacang telur dan kacang Kentucky yang dihasilkan dikemas dalam kemasan platik sementara selai kacang dikemas dalam toples plastik. kemudian diberi label hasil desain mahasiswa.

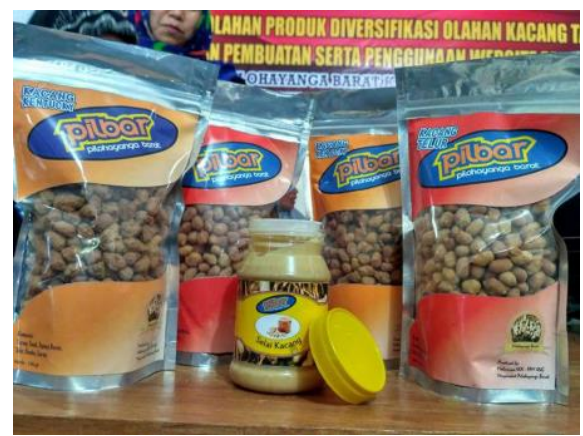

Pada pelatihan ini, selain pemberian materi dan praktek, juga telah dibentuk 3 kelompok masyarakat yang bersedia membentuk UMKM. Nama- nama UMKM yang terbentuk antara lain:

1. "UMKM Berkah" yang terdiri atas 11 orang anggota,

2. "UMKM Bersahaja" yang terdiri atas 6 orang anggota

3. "UMKM Sejahtera" yang terdiri atas 6 orang anggota

Selain terbentuknya 3 UMKM di atas, pada pelatihan ini juga tercetus brand khusus produk Pilohayanga Barat yaitu "PILBAR" yang merupakan singkatan dari Pilohaynga barat. Brand ini yang akan digunakan untuk seterusnya pada setiap kemasan produk kacang dari Pilohayanga Barat. Dengan adanya brand ini 
diharapkan dapat mempermudah promosi dan pengenalan produk di masyarakat luas.

\section{Pelatihan Pembuatan dan Penggunaan Website Penjualan}

Selain diberikan pelatihan pengolahan, peserta juga diberikan pelatihan pembuatan dan penggunaan website penjualan, untuk menunjang penjualan. Seperti telah diketahui, era sekarang penjualan online mendatangkan potensi yang jauh lebih besar dibandingkan dengan penjualan langsung. Karena kemudahan sistem online membuat pembeli tidak perlu bersusah payah datang ke tempat penjualan, khususnya pembeli yang berasal dari luar daerah. Dengan dibuatnya website penjualan diharapkan dapat mempermudah promosi dan penjualan produk dari UMKM yang telah dibentuk. Pada pelatihan ini masyarakat terlebih dahulu diberikan materi mengenai pentingnya strategi penjualan online, kemudian dilakukan praktek pembuatan dan penggunaan website penjualan. Dalam website ini telah dirancang khusus layaknya website penjualan lainnya, yaitu dilengkapi dengan informasi produk, termasuk komposisi dan harga produk, serta dilengkapi dengan menu belanja, sehingga pengunjung bias memesan langsung lewat website ini dengan menglik icon "beli" dan sampai pada tahapan transaksi penjualan.

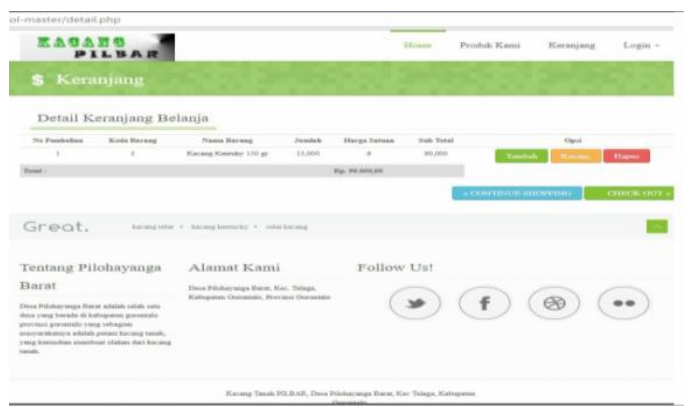

Gambar 3. Tampilan Website Penjualan yang telah dibuat

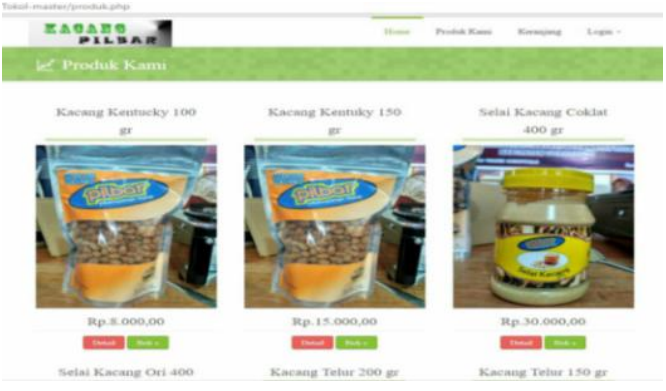

\section{Hasil Uji Organoleptik Produk yang dihasilkan}

Uji organoleptik ini dilakukan sebagai salah satu parameter penting dalam produk pangan dengan tujuan untuk mengetahui seberapa jauh penerimaan panelis terhadap produk yang dihasilkan. Pengujian tingkat kesukaan konsumen dilakukan dengan menggunakan metode skala hedonik dengan menggunakan 30 panelis tidak terlatih yaitu mahasiswa KKS Pengabdian. Pengujian tingkat kesukaan panelis terhadap sampel kacang telur, kacang kentucky dan selai kacang yang dihasilkan dari pelatihan ini meliputi penilaian terhadap warna. Sedangkan hasil pengujian hedonik dari dari masing-masing produk hasil pelatihan dapat dilihat pada Gambar 1,2 dan 3 .

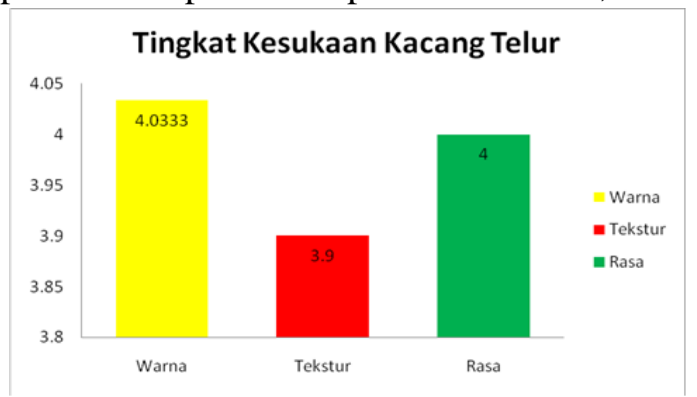

Gambar 4. Uji hedonik terhadap rasa, warna dan tekstur kacang telur hasil pelatihan

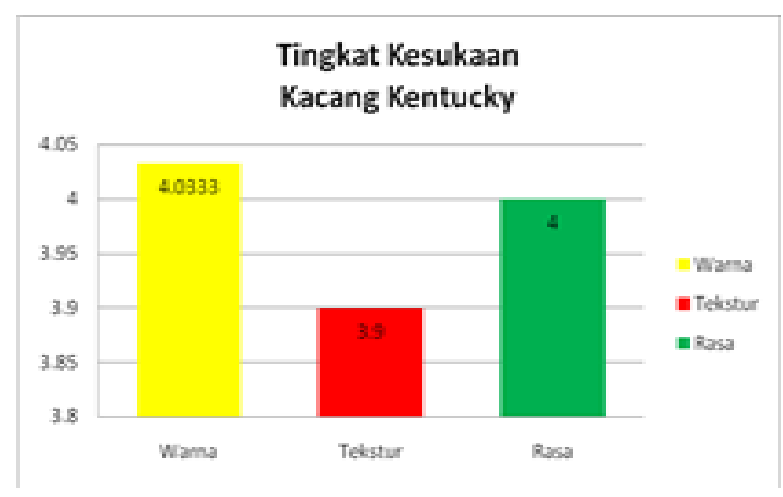

Gambar 5. Uji hedonik terhadap rasa, warna dan tekstur Kacang Kentucky hasil pelatihan 


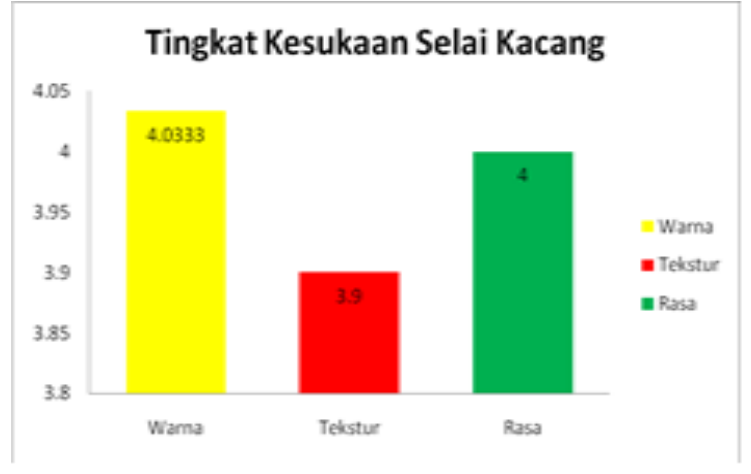

Gambar 6. Uji hedonik terhadap rasa, warna dan tekstur selai kacanghasil pelatihan.

Warna adalah indikator pertama yang langsung diamati oleh konsumen karena warna merupakan faktor kenampakan yang langsung dilihat oleh indera penglihatan Warna yang menarik merupakan hal yang penting karena warna merupakan daya tarik penjualan yang langsung dan mempengaruhi respon organoleptik terhadap flavour yang pada akhirnya sangat menentukan penerimaan konsumen. Hasil pengujian organoleptik pada Gambar 1, 2 dan 3 di atas menunjukkan bahwa tingkat preferensi konsumen terhadap warnakacang telur, kacang kentucky dan selai kacang berada pada rangesuka dengan nilai 4 .

Gambar histogram di atas juga menunjukkan bahwa panelis menyukai tekstur dari kacang telur, kentucky dan selai kacang yang dihasilkan oleh peserta dengan nilai ratarata 4. Tekstur dari kacang telur dan kacang kentucky itu renyah seperti sedangkan sedangkan selei kacang teksturnya sangat lembut.

Karakteristik rasa dari suatu produk makanan merupakan salah satu faktor utama penerimaan konsumen terhadap produk tersebut. rasa suatu bahan makanan merupakan hasil kerjasama indera-indera lain, seperti indera penglihatan, pembauan, pendengaran dan perabaan (Kartika dkk, 1988 dalam Rini, 2008). Hasil uji hedonik terhadap rasa dari kacang telur, kacang kentucky dan selai kacang berdasarkan histogram di atas (Gambar 1, 2 dan 3) menunjukkan bahwa ketiga produk tersebut disukai oleh panelis dengan nilai rata-rata 4 .

\section{Pendampingan Produksi, Promosi Dan Penjualan}

Dalam kegiatan pengabdian ini, salah satu output yang diharapkan adalah peningkatan produksi dan pendapatan masyarakat. Selain pemberian pelatihan dan pembentukan UMKM, program KKN-PPM ini juga memberikan pendampingan kepada UMKM yang telah dibentuk, dalam hal produksi, promosi dan penjualan. Untuk produksi, mahasiswa KKNPPM telah dibagi kedalam 3 kelompok besar, dimana tiap 1 kelompok akan bertanggungjawab mendampingi produuksi 1 UMKM. Kegiatan produksi dilakukan sebanyak seminggu sekai atau seminggu 2 kali.

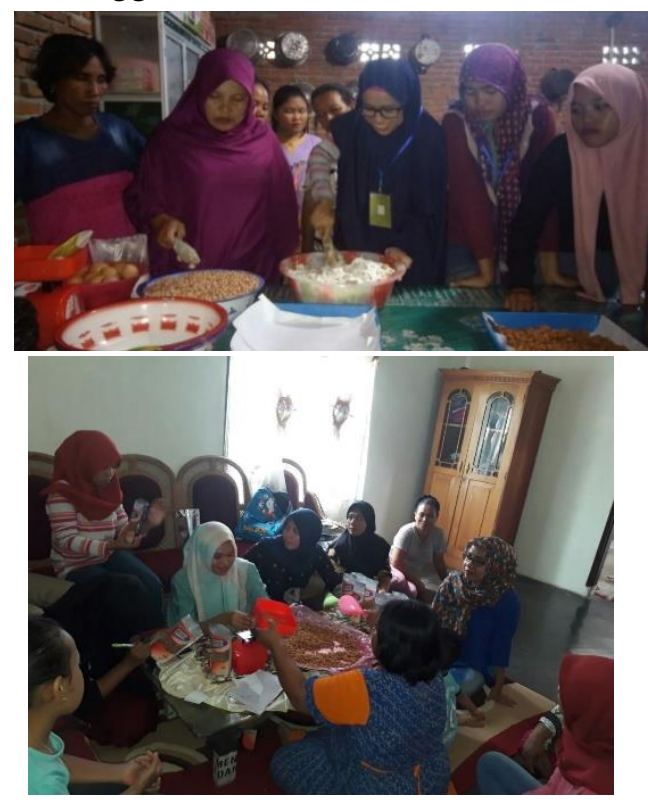

Gambar 7. Kegiatan Pendampingan produksi oleh mahasiswa KKN-PPM

Untuk kegiatan promosi, ada beberapa mahasiswa yang telah ditunujuk untuk bertanggung jawab dalam promosi produk. Promosi dilakukan dengan cara menyebar brosur di beberapa tempat keramaian, dan dilakukanan melalui online.
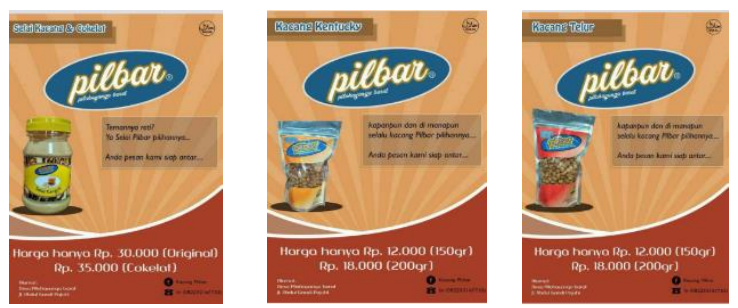
Gambar 8. Brosur Promosi Produk

\section{Kesimpulan}

Pelaksanaan program inti yang dilaksanakan pada kegiatan KKN-PPM ini terlaksana dengan baik. Hal ini dapat dilihat bahwa $100 \%$ peserta pelatihan berpartisipasi aktif dalam kegiatan mulai dari penyajian materi sampai pada kegiatan praktikum pada pelaksanaan program utama KKN-PPM. Selain itu peserta pelatihan sudah mampu melakukan proses pengolahan kacang telur, kacang kentucky dan selai kacang yang terlihat dari karakteristik produk yang mereka hasilkan. Hasil pengujian organoleptik dari semua produk tersebut disukai oleh panelis serta layak untuk dipasarkan. Selain itu dari kegiatan inti ini telah terbentu 3 kelompok UMKM yang menjalankan usaha pengolahan kacang.

\section{DAFTAR PUSTAKA}

BPS. 2013. Gorontalo Utara dalam Angka. Gorontalo 2013
Kasim. R dan Y.Bait. 2007. Pelatihan Pembuatan Dodol Kacang tanah Di Kelurahan Tuladenggi Kecamatan Dungingi Kota Gorontalo (Laporan PPM). UNG.

Kasim, R. Dan Marleni Limonu.2015. Inovasi Teknologi Melalui Upaya diversifikasi pangan olahan berbasis kacang tanah di Desa Nanati Jaya (Laporan KKSPengabdian).UNG

Lay. A. . P.M Pasang dan D.J. Torar. 2004. Perkembangan Teknologi Pengolahan Minyak Kelapa. Monograf Pascapanen Kacang tanah Balitka Manado. ISBN 979-98976-09

LPM.2015. Panduan Pelaksanaan KKNPPM.LPM Universitas Negeri Gorontalo. 